\title{
Configuração da condição operária numa época de recon- figuração do modo de produção capitalista no Brasil
}

\author{
Danilo Lucena Mendes ${ }^{1}$
}

\begin{abstract}
Resumo: 0 objetivo principal deste artigo é analisar o processo de transformação da relação salarial na transição da Primeira República para o Primeiro Governo Vargas (1930-1945). Com base na formulação de Robert Castel - em seu diálogo com a Escola Francesa da Regulação - sobre o conceito de relação salarial, consideramos tal período como uma transição da condição proletária para a condição operária. Apoiando-se em alguns trabalhos clássicos sobre as relações de trabalho no Brasil, operamos uma mediação das principais noções utilizadas por Castel (relação salarial; condição proletária; e condição operária) para construir um quadro teórico adequado à nossa particularidade histórica. Paralelamente, procuramos entender como algumas condições colocadas pelo processo de industrialização atuaram sobre a configuração da condição operária. Nesse sentido, entendemos que no processo de industrialização desencadeado no pós-1930, tivemos, no Brasil, uma superação relativa da condição proletária e uma constituição, também relativa, da condição operária.
\end{abstract}

Palavras-chave: relação salarial; condição proletária; condição operária; industrialização

\section{Introdução}

Comum à Escola Francesa da Regulação $(E F R)^{2}$, o conceito de relação salarial foi apropriado e ressignificado por Robert Castel em seu clássico trabalho "As metamorfoses da questão social - uma crônica do salário". Se os regulacionistas elaboraram o conceito de relação salarial para pensar as formas de regulação das relações de trabalho durante o período que ficou conhecido como fordista (1945-1975, aproximadamente), Castel toma-o de outra maneira. No registro casteliano o conceito de relação salarial foi mobilizado para "evidenciar as transformações que comandam a passagem de uma forma [de relação salarial] a outra" tendo em vista que "no seio de uma mesma formação social, o capitalismo, a relação salarial pode assumir diferentes configurações" (CASTEL, 1998, 419).

As condições proletária e operária são diferentes configurações assumidas pela relação salarial sob o capitalismo. Cinco condições atuaram para "assegurar a passagem da relação salarial que prevalecia no começo da industrialização à relação salarial fordista [...]." (CASTEL, 1998, pp. 419-20). São elas: uma "nítida separação entre os que trabalham efetiva e regularmente e os inativos ou semi-inativos"; "a fixação do trabalhador em seu posto de trabalho e a racionalização do proces-

\footnotetext{
1 Graduando/Mestrando em Ciências Sociais - USP

2 A EFR formou-se na década de 1970 tendo como preocupação a crise que assolava o capitalismo depois dos "trinta anos gloriosos". Problematizavam, especificamente, o crescimento e as crises capitalistas; suas variações no tempo e no espaço; sem perder de vistas as mediações, isto é, as formas sociais que comandam tais variações (cf. NASCIMEnTo, 1993). Dentre as várias vertentes da EFR destaca-se a Escola Parisiense formada por aqueles que produziram os trabalhos mais difundidos, quer seja dentro da academia, quer seja no âmbito da administração econômica do Estado (cf. BRAGA, 2002). Michel Aglietta, Robert Boyer e Alain Lipietz são os autores mais representativos da Escola Parisiense (cf. BocCi 2000).
} 
so de trabalho"; o acesso a bens duráveis através de um salário regular; "o acesso à propriedade social e aos serviços públicos"; e a instituição de um estatuto coletivo do trabalho, sem anulação da dimensão individual do contrato de trabalho (CASTEL, 1998, pp. 420-436).

Essas cinco condições estavam presentes nas transformações da relação salarial ao longo da industrialização francesa e inglesa, tomados como casos clássicos. Mas, também, de algum modo apareceram e intervieram nos países ocidentais que se industrializaram nos séculos XIX e XX. Nesse sentido, Castel remete explicitamente a Karl Polanyi que, segundo ele, perfaz a tese de que

\footnotetext{
os Estados sociais dos países ocidentais responderam ao desafio comum, o da industrialização e dos fatores de dissociação social que ela acarretava; mas, evidentemente, o fizeram em ritmos distintos, mobilizando suas tradições nacionais e levando em conta as diferentes forças sociais presentes em cada contexto. (CASTEL, 1998, p. 17)
}

Nossa hipótese é de que no Brasil configurou-se um tipo particular de relação salarial forjada no processo de industrialização e expansão capitalista do pós-1930. Consequentemente, colocam-se as seguintes questões: quais são as características dessa relação salarial? E, quais são as forças sociais que fizeram com que ela emergisse de determinada forma e não de outra?

\section{Relações salariais}

A formulação casteliana de relação salarial traz uma questão não negligenciável: tendo em vista que tal conceito foi pensado para dar conta da relação salarial tipicamente fordista, sob que condições podemos afirmar a existência de uma relação salarial correlata à condição proletária? Ou seja, anterior ao fordismo?

Em termos genéricos, Castel e os regulacionistas compartilham a definição de que se uma relação de compra e venda de força de trabalho comportar uma "forma de remuneração do trabalho"; "uma disciplina do trabalho"; e "uma forma jurídica que regula o uso da força do trabalho", então podemos considerá-la como uma relação salarial (CASTEL, 1998, p. 419).

Sob a luz de tal definição, como se configuraria a condição proletária? Em outras palavras, é possível afirmar que sob a condição proletária havia uma forma de remuneração do trabalho?

Esta questão nos conduz para um contexto histórico específico, as relações de trabalho nos primórdios do desenvolvimento do capitalismo industrial dominado pelas manufaturas e pelo sistema de encomendas. Atendo-nos a este contexto, po- 
demos afirmar que havia remuneração do trabalho (em forma de moeda), ainda que de forma irregular e variável, ou seja, de acordo com as tarefas executadas, quando estas eram oferecidas. Também podemos afirmar que havia uma disciplina do trabalho, pois, de um lado, quando o trabalho era realizado em casa por encomenda de fora - putting out system - a disciplina era imposta pelo tempo em que a produção deveria estar disponível para o contratante. De outro, desde o momento em que o trabalho passa a ser realizado fora de casa nos primeiros estabelecimentos fabris, surgirá a figura do inspetor de fábrica que tem como função disciplinar a força de trabalho impedindo o desperdício de tempo. Temos, assim, uma disciplina em torno da realização do trabalho. Por fim, tem-se uma forma jurídica que regulamenta o uso da força de trabalho também. É sob a forma do contrato entre indivíduos livres e perseguidores de seus próprios interesses que o liberalismo legitima a relação de compra e venda da mercadoria força de trabalho (MARx, 1996, p. 293). A presença dessas relações como marca de uma relação salarial específica (condição proletária) permite que Robert Castel pense na transformação histórica da relação salarial, e a entenda não como exclusiva de um período histórico particular (o fordismo, ou o capitalismo regulado, segundo a formulação da EFR.).

Para explicar as transformações que comandam a passagem da condição proletária para a condição operária, portanto, a transformação da relação salarial, Castel aponta para a presença, como vimos, de cinco condições. Da primeira à quinta condição ele acentua como cada uma assumiu uma funcionalidade única contribuindo, cada uma do seu modo, para configurar a transformação da relação salarial. Em cada uma dessas condições ele identifica elementos típicos do processo de racionalização, comum às sociedades ocidentais de desenvolvimento capitalista. 0 uso da estatística para estimar a população de trabalhadores ativos; a referência à mecanização do processo de trabalho cuja consequência foi a fixação do trabalhador a um posto de trabalho (especialização), que, por sua vez, aparece como umas das pré-condições de uma remuneração fixa. Por outro lado, o Estado, não gratuitamente, assumirá responsabilidades para com os trabalhadores, disponibilizando serviços públicos, ao mesmo tempo em que os trabalhadores são reconhecidos como atores políticos legítimos, partidos e sindicatos trabalhistas são legitimados.

No esforço de entender a realidade brasileira tomando como base este quadro teórico, não podemos seguir caminho idêntico ${ }^{3}$, pois se trata de outro desenvol-

3 Obviamente que aquelas cinco condições não podem ser entendidas como estáticas e fechadas, de tal modo que, ao longo do tempo, uma fosse necessariamente se somando à outra depois de prontas para gerarem o mesmo produto. Mas, pelo contrário, elas vão sendo moldadas pelo conflito entre os atores principais das sociedades industriais - burguesia, proletariado e Estado - de tal modo que tendem, ao longo do tempo, a determinar um ajustamento dos diversos interesses. Pensar de outro modo seria subestimar a capacidade intelectual do autor. 
vimento histórico. Nesse sentido, procuramos nos ater à totalidade das relações que abarcaram a passagem da relação salarial correlata à condição proletária para aquela correlata à condição operária, no Brasil. Para tanto, demos ênfase não ao surgimento das condições em si, mas à dialética do conflito tríplice entre a classe trabalhadora (urbano-industrial), a burguesia (em suas frações agrária e industrial) e o Estado (Liberal e Corporativista). Esta tríplice relação não acontece no vácuo, mas sob determinadas condições legadas por um tipo particular de desenvolvimento capitalista. Por isso, procuramos entender quais foram as determinações que o capitalismo dependente brasileiro (FERNANDES, 2005; OLIVEIRA, 2003) impôs à configuração da condição operária entre nós.

\title{
O proletário e o operário, suas condições
}

0 trabalhador despossuído de meios de produção é uma das condições indispensáveis para o desenvolvimento do capitalismo industrial, uma vez que é o elemento fundamental de uma de suas instituições básicas, o mercado de trabalho. ${ }^{4} \mathrm{~A}$ mercantilização da força de trabalho é, nesse sentido, o processo pelo qual a força de trabalho passa a ser negociada em um mercado como qualquer mercadoria. 0 trabalho sob a forma de mercadoria é uma ficção que teve como função estabelecer as bases da economia de mercado, como Polanyi designa o capitalismo. Seu efeito prático foi depauperar a classe trabalhadora, colocando todo o tecido social sob o risco de desintegração.

\begin{abstract}
Permitir que o mecanismo de mercado seja o único dirigente do destino dos seres humanos e do seu ambiente natural, e até mesmo o árbitro da quantidade e do uso do poder de compra, resultaria no desmoronamento da sociedade. Esta suposta mercadoria, "a força de trabalho", não pode ser impelida, usada indiscriminadamente, ou até mesmo não-utilizada, sem afetar também o indivíduo humano que acontece ser o portador dessa mercadoria peculiar. Ao dispor da força de trabalho de um homem, o sistema disporia também, incidentalmente, da entidade física, psicológica e moral do "homem" ligado a essa etiqueta. Despojados da cobertura protetora das instituições culturais, os seres humanos sucumbiriam sob os efeitos do abandono social; morreriam vítimas de um agudo transtorno social, através do vício, da perversão, do crime e da fome. Os mercados de trabalho, terra e dinheiro são, sem dúvida, essenciais para uma economia de mercado. Entretanto, nenhuma sociedade suportaria os efeitos de um tal sistema de grosseiras ficções, mesmo por um período de tempo muito curto, a menos que a sua substância humana natural, assim como a sua organização de negócios, fosse protegida contra os assaltos desse moinho satânico. (PolANYI, 2000, pp. 94-95)
\end{abstract}

$4 \quad$ Braudel (1996) define assim o mercado de trabalho: "O mercado de trabalho é aquele em que um homem, venha de onde vier, se apresenta despojado de seus tradicionais "meios de produção", supondo que alguma vez os teve: uma terra, um tear, um cavalo, uma carroça... Ele só tem a oferecer as mãos, os braços, suas "força de trabalho". E, claro, sua habilidade. O homem que se aluga ou se vende desse modo passa pelo buraco estreito do mercado e sai da economia tradicional." (BRAUDEL, 1996, P. 37) 
A primeira característica da condição proletária é a sua situação de quase exclusão do corpo social. Na medida em que não estavam integrados à sociedade capitalista - apenas enquanto sub-cidadãos, tendo em vista que não tinham nem direitos políticos nem sociais, mas apenas os direitos civis que os tornavam aptos para estabelecer relações jurídicas com outras figuras jurídicas - tal relação era, sobretudo, a relação de venda da força de trabalho pelo trabalhador individual, e de compra por parte do capitalista.

Uma alta rotatividade nos postos de trabalho, ocupados apenas temporariamente pelos trabalhadores, em parte por causa da extensa jornada de trabalho, era mais uma marca dessa condição. Ao elevado turn over correspondia uma remuneração irregular, de acordo com a tarefa cumprida no trabalho, quando havia a possibilidade de trabalhar. Nestas circunstâncias o proletário trabalhava basicamente para reproduzir-se enquanto força de trabalho, não porque quisesse, mas porque essas eram as circunstâncias que o mercado de trabalho desregulamentado lhe impunha. Por conseguinte, seu padrão de consumo era caracterizado pelo consumo dos meios de subsistência apenas. ${ }^{5}$

Uma vez em luta, o movimento dos trabalhadores configurou-se como o movimento social da sociedade industrial, o seu eterno fantasma. 0 conflito de classe era explícito e inevitável em tais condições (HoBsBAWM, 1996). Seu aprofundamento fez pouco a pouco o movimento dos trabalhadores lograr a criação de canais por meio dos quais foi socialmente integrado.

Se a condição proletária foi "marcada por uma vulnerabilidade de todos os momentos" (CASTEL, 1998, p. 444). A condição à qual o trabalhador industrial ascendeu assumirá outros contornos. Uma vez instituído, o salário implica em um aumento do consumo, o que, por sua vez, implica em um incremento da produção. Contudo, os salários não aumentariam sem que fossem implantadas algumas condições técnicas que garantissem uma maior produtividade do trabalho. A mecanização da produção e/ou a cronometragem de tempos e movimentos do processo de trabalho foi o que permitiu uma remuneração do trabalho regular, porque mensal; e fixa, porque baseada em uma estimação mais precisa do tempo de trabalho necessário despendido a cada jornada de trabalho. Tudo isso impactou no consumo e produtividade do trabalhador. A nova relação salarial configurava-se, assim, como uma forma ótima de regulação do conflito entre capital e trabalho, pois parecia ser um bom negócio tanto para os trabalhadores como para os patrões.

Superada, parcialmente, a condição proletária, a sociedade industrial atin-

5 "O proletariado é um elo essencial no processo de industrialização nascente, mas está condenado a trabalhar para se reproduzir e, segundo a expressão já citada de Auguste Comte, "acampa na sociedade sem se encaixar"." (CASTEL, 1998, p. 415). 
giu uma estabilidade política relativa. Quando a nova relação salarial encontra-se estabelecida no âmbito das relações da sociedade industrial o trabalhador já não é mais tão somente um proletário, mas ascende, por assim dizer, à condição operária. Esta, contudo, apresenta duas particularidades: os trabalhadores são sujeitos políticos legítimos, logo são integradas à vida social mais ampla, mas trata-se de uma integração subordinada. ${ }^{6}$

Até aqui vimos o processo de transformação da relação salarial tomando-se por base um movimento histórico mais geral, posto que nos referimos às interpretações elaboradas no centro do capitalismo. De agora em diante tomamos mais de perto o contexto periférico do capitalismo, tal como ele se desenvolveu no Brasil.

\title{
Proletariado e ideologia laissez-fairiana na Primeira República
}

Enquanto a condição proletária é dominante a sociedade industrial encontra-se cindida entre um grupo a ela integrado e outro parcialmente integrado; assim, configura-se um tipo de sociedade dual. ${ }^{7}$ Esta se encontra em constante risco de desagregação. A consciência daqueles que se encontram na condição proletária é marcada por uma cisão que divide o mundo social em duas categorias: "eles", os patrões exploradores que não têm que se matar de trabalhar para sobreviver, e, apesar disso, se apropriam da riqueza socialmente produzida; e "nós", os honrados trabalhadores, produtores de toda a riqueza material de que a sociedade necessita. De algum modo, a sociedade industrial brasileira entre o final do século XIX até as duas primeiras décadas do século XX assumiu a forma de uma sociedade dual.

\begin{abstract}
a Primeira República preservou as condições que permitiam, sob o Império, a coexistência de "duas nações", a que se incorporava à ordem civil (a rala minoria, que realmente constituía uma "nação de mais iguais"), e a que estava dela excluída, de modo parcial ou total (a grande maioria, de quatro quintos ou mais, que constituía a "nação real"). (FERNANDEs, 2005, p. 242).
\end{abstract}

A Primeira República também pode ser entendida como uma "tentativa de organizar a vida econômica e social no país segundo princípios laissez-fairianos ortodoxos" que "expande-se, teoricamente, da abolição do trabalho escravo, em 1988, até 1931." (SANTOS, 1987, p. 64)

A ideia de tentativa é adequada porque a aplicação dos princípios laissez-

\footnotetext{
6 “[...] o particularismo operário, sua destinação para ocupar um lugar subordinado na divisão do trabalho social e na sociedade global." (CASTEL, 1998, p. 437).

7 "Uma sociedade dual é uma sociedade de exclusão em que de certos grupos não têm nada e não são nada, ou quase nada." (CASTEL, 1998, p. 444).
} 
-fairianos são politicamente limitados e têm vida breve. De um lado, a vigência de princípios liberais no mercado de trabalho ficou restrita à cidade. ${ }^{8}$ De outro lado, no princípio da década de vinte inicia-se a produção de leis sociais efetivas, ainda que sob a forma de acordos privados, que indicavam o "reconhecimento da insuficiência dos automatismos do mercado" para garantir mínimas condições de vida para os trabalhadores industriais. Com efeito, a "hegemonia do laissez-faire teve vida curta no Brasil", pois esteve "restrita à área urbana, entre 1888 e 1931, no que concerne à economia, e vulnerada a partir de 1923 no que diz respeito às relações sociais." (SAntos, 1987, p. 65). 0 ano de 1923 é apontado por Santos como o começo do fim da hegemonia laissez-fairiana porque esse ano marca o início dos esforços institucionais para fundar um marco regulatório para a questão social.

O mercado de trabalho na cidade de São Paulo "caracterizava-se, no período pré-1930, pela extrema flexibilidade da mão-de-obra, ausência de obrigações contratuais por parte dos empregadores e por uma elasticidade da oferta impressionante". E, outro traço definidor da condição proletária também se fazia presente: "Os salários não eram de equilíbrio, mas definidos pela força do empregador"; mas, sua variação dependia do "tipo de especialização exigido, da existência de ação sindical e do grau de avanço tecnológico". (BARBosA, 2008, pp. 105-6).

A luta organizada dos trabalhadores fez com que o Estado passasse a interferir institucionalmente no que diz respeito ao uso e abuso do trabalho enquanto mercadoria. A interferência do Estado no âmbito das relações de trabalho criou um "descompasso entre a política social compensatória [...] e a política via regulação do processo acumulativo, que só se iniciará após a revolução de 1930." Tal descompasso atravessa toda a década de 1920. A saída não poderia deixar de passar pela alteração das "normas que presidiam o processo de acumulação e as relações sociais que aí se davam." (SANTos 1987, p.66).

\section{Pura dominação burguesa impossível, dominação corporativa e configura- ção da condição operária}

A Revolução de outubro de 1930 definida como marco divisor da relação do Estado brasileiro com a questão social; e o discurso segundo o qual as leis do trabalho foram outorgados por um Estado benevolente; são ideias que pela força com que

8 “...] as relações de trabalho no setor agrícola da economia jamais chegaram a se aproximar das condições da acumulação laissez-fairiana clássica. A penetração das leis do mercado na economia agrária brasileira se fez muito em flagrante descompasso com o ritmo de implantação da ordem capitalista na área urbana. A prevalência ideológica do laissez-faire é, portanto, restrita à área urbana da sociedade, cujas relações econômicas e sociais deveriam pautar-se pelos princípios que regeram as organizações sociais europeias no período que vai do início da industrialização às primeiras leis de regulação social." (SANTOS, 1987, p. 64-5). 
foram impostas, pelos intelectuais do regime estadonovista, adquiriram, por algum tempo, o estatuto de verdades absolutas (VIANnA, 1999). Mas, se a partir de 1930 a questão social, de fato, assumiu centralidade dentre as preocupações dos dirigentes do Estado não foi sem motivo, ou, tão somente por boa vontade. 0 discurso que afirmava o caráter de outorga do Estado pós-1930, com relação às leis do trabalho, ao mesmo tempo, velava a precedente pressão política exercida pelo movimento operário nas décadas que antecederam a "Revolução". ${ }^{9}$

Desde a fundação da República, uma Constituição de caráter liberal sustentava a possibilidade de uma "dominação burguesa em sua modalidade plenamente hegemônica" (VIANNA, 1999, p.106). O Estado assim constituído sustentava-se no pacto entre a burguesia agrária e a burguesia industrial. Por isso, esta última sequer considerará a necessidade de insurgir-se contra a fração agrária da burguesia. E não o fará, pois a ordem oligárquica pré-1930 assenta-se muito bem aos seus moldes de dominação.

Contudo, quando em 1919 a ortodoxia liberal é rompida, abrindo o caminho para uma crescente intervenção do Estado nas relações de produção que se mostrará ao longo da década de 1920, e de modo mais explícito em 1926, (VIANNA, 1999) à burguesia não restará alternativa se não a de sair do estreito horizonte da fábrica e organizar-se politicamente. Em movimento a burguesia industrial, primeiro, alardeará sobre a ameaça que constituem as leis do trabalho para o aumento da riqueza na nação; num segundo momento, defenderá as ideias liberais, quando, então, esboçará um projeto de sociedade tipicamente burguês.

Do ponto de vista da burguesia agrária, controladores do Estado, a questão social se tornou negociável quando, depois do ciclo de greves proletárias que encerrou a segunda década do século, "os apuros operários despertaram na classe média urbana uma certa dose de simpatia." (ViannA, 1999, p. 109). Afinal a inflação e a escassez de gêneros alimentícios básicos também a afligia. Os anos 1920 são, portanto, de crise econômica, política e social. Esta conjuntura crítica provocou uma rachadura no bloco burguês e impedia a continuidade de tal arranjo político.

Nem a facção agrário-exportadora, nem a industrial, poderiam manter sua tradicional postura liberal. A primeira, acossada pelas pressões de-

9 Por meio da noção de trabalhismo, Ângela de Castro Gomes (1988) entende que Vargas tinha um projeto de Estado que resultou no processo pelo qual a classe trabalhadora se configurou como ator político legítimo. 0 sucesso deste projeto é que condiciona toda uma visão de 1930 como ruptura absoluta e a ideologia da outorga. Seu sucesso se deve ao fato de que "o projeto estatal que constituiu a identidade coletiva da classe trabalhadora articulou uma lógica material, fundada nos benefícios da legislação social, com uma lógica simbólica, que representava estes benefícios como doações e beneficiava-se da experiência de luta dos próprios trabalhadores". Nesse sentido, o trabalhismo consistiu em "um fenômeno político cultural capaz de articular valores, ideias, tradições e modelos de organização através de um discurso em que o trabalhador é ao mesmo tempo sujeito e objeto." (Gomes, 1988, p.23). 
mocratizadoras de uma sociedade que ela mesma desenvolvia e tornava complexa, não contava com recursos políticos, econômicos e sociais para satisfazer o nível de suas demandas. [...] Uma generalização real da política do Estado pressupunha seu deslocamento do eixo dinâmico da sociedade. A segunda, em razão de suas necessidades de acumulação de capital, que não poderia resistir à democratização do pacto liberal, com o subsequente acréscimo da capacidade reivindicadora da classe operária. (VIANNA, 1998, pp. 131-2).

A impossibilidade de se firmar o reino do puro interesse individual interditava à burguesia industrial alcançar a condição de classe hegemônica. A alternativa foi integrar-se aos planos do Estado Corporativista que estava se configurando.

A adesão da burguesia industrial ao Estado Corporativista não se deu de modo imediato, mas através de sucessivos avanços e recuos. Se isso, por um lado, evidenciava a crise de hegemonia da burguesia industrial; por outro, dissimulava sua dominação, justamente porque encontrava-se imbricada neste novo tipo de dominação. Com efeito, o projeto corporativista veio catalisar o processo de acumulação de capital com base no controle dos sindicatos e do movimento operário. A diferença entre o corporativismo e o liberalismo ortodoxo da Primeira República era tão somente o fato de que sob o corporativismo nenhuma classe parecia exercer a dominação social, posto que o Estado assumiu uma figura conciliatória e seus intelectuais construíram o belo conto da outorga.

Mas isso não é tudo. Como explicar que um Estado corporativista organize as condições para a dominação da burguesia industrial, ainda que mascarada? A noção de autonomia política do Estado é enfatizada por Vianna como a condição para que se efetivasse a dominação burguesa. A autonomia do Estado na política significa que este tem a capacidade de arranjar o conflito político de modo a parecer que estava governando para o bem de todos, quando na verdade estava abrindo a pista para o capitalismo industrial decolar. É a partir desse momento, portanto, que o capitalismo industrial ocupará o centro das atenções do Estado brasileiro. Este não mediu esforços para estabelecer as bases da modernização das forças produtivas, a industrialização - nas palavras de Celso Furtado (1989), para promover "a mudança do eixo dinâmico da economia brasileira".

Sem perder de vista este concerto, Vianna aborda os problemas e as implicações da transição das relações de trabalho agrárias para aquelas típicas do capitalismo. Um problema particularmente importante para o caso brasileiro tendo em vista seu passado de produção baseada no latifúndio.

A arguta percepção de Vianna nos chama a atenção para um fato que torna o problema mais sério ainda, sobretudo em suas implicações para a formação da condição operária no Brasil. Dada a crise de hegemonia da burguesia industrial que 
se expressa no final da década de 1920, é a fração agrária não exportadora (isto é, também ligada à posse de latifúndios, mas cuja produção era destinada ao mercado interno) que sustentará o necessário projeto de modernização do Estado Brasileiro. 0 papel de dirigente do projeto de modernização estava interditado não só à burguesia industrial, mas também à tradicional burguesia agroexportadora; logo, dentro do bloco burguês, era aquela fração a única em condições de conduzir esse processo. Por isso, é que será possível a execução de um projeto que comporta soluções para os problemas do industrialismo burguês - subordinando os interesses operários aos interesses da burguesia -, contudo, sem ferir os interesses da fração burguesa tradicionalmente situada no campo. Isto é, sem modernizar as relações de produção no campo e, assim, garantindo o estatuto secular do latifúndio.

A intensa atração que o setor urbano-industrial da economia exercerá sobre os trabalhadores alocados em relações de produção pré-capitalistas, está ligada a este fato. Isto afetará diretamente o padrão de vida da classe operária nos centros industriais. Mas para o capitalismo industrial nada melhor que as fileiras do exército industrial de reserva se avolumassem mais e mais. Nesse sentido, Vianna afirma que a condição sine qua non para a transição do agrarismo para o capitalismo industrial foi a manutenção do estatuto do campo. Por isso que a transição para o capitalismo industrial no Brasil caracterizou-se como um processo de modernização conservadora.

O fundamental para a compreensão da especificidade da condição operária tal como foi configurada no Brasil está no fato de que, uma vez compreendido o concerto político entre as frações burguesas, deve-se considerar que a estrutura sindical corporativista foi construída com o objetivo de desmobilizar a classe operária. Com isso, evidencia-se que a subordinação da classe operária no Brasil era diretamente política, assumindo depois um caráter social.

Segundo nos diz Castel, o padrão de vida do proletariado, na França, era ligeiramente inferior ao de outros segmentos assalariados, eis o particularismo da condição operária: ser simbolicamente subordinada tendo em vista sua posição social. No Brasil, a subordinação não é primeiramente social, mas política, garantida pelo corporativismo, que está particularmente articulado ao tipo de capitalismo dependente brasileiro.

O corporativismo negou ao proletariado a possibilidade de constituir-se como ator coletivo totalmente autônomo. A burguesia, bem assentada no corporativismo, dizia que um estatuto coletivo do trabalho ia contra a ortodoxia corporativista que pregava que os interesses individuais de uma classe não poderiam subsumir os interesses da nação. 0 princípio de luta coletiva operária era tornado, nesta chave, in- 
dividualista, por que expressão de interesses particulares de uma classe. Com isso, a condição operária que aqui foi configurando-se, em comparação com aquelas condições colocadas por Castel, assume uma forma incompleta. Tomando-se por base a ilegitimidade de organizações sindicais autônomas, os operários são integrados de modo subordinado na dimensão social e, sobretudo, na dimensão política do capitalismo brasileiro.

\section{Os constrangimentos do capitalismo industrial periférico brasileiro sobre a condição operária}

Francisco de Oliveira é enfático ao afirmar que a Revolução de 1930 marca o fim de uma e o começo de outra era na economia brasileira. Nessa transição ocorreu a destruição das regras do jogo sob as quais a anterior se mantinha; e se estabeleceu novas regras para sustentar um novo tipo de acumulação. Dentre estas regras, a ação estratégica do Estado, no sentido de criar os meios mais adequados para o desenvolvimento da indústria, a regulamentação do fator trabalho e o papel estratégico desempenhado pela agricultura, ambos direcionados para garantir uma crescente acumulação de capital industrial, são os elementos fundamentais desse processo.

Considerado como um fator de produção fundamental para a indústria, a regulamentação do trabalho será, então, imprescindível. Trata-se do elemento catalisador do desenvolvimento industrial que vai caracterizar-se pela "realização parcial interna crescente" de mais-valia. "O decisivo é que as leis trabalhistas fazem parte de um conjunto de medidas destinadas a instaurar um novo modo de acumulação." (OLIVEIRA, 2003, p. 38)

A lei que deveria regulamentar o salário mínimo é de 1934, mas sua primeira tabela saiu apenas em 1939 (VIAnNA, 1999). Nesse intervalo de cinco anos, o mínimo não foi respeitado pelo empresariado sob a alegação de que corroeria os lucros. 0 mínimo, de fato, correspondia ao mínimo do valor monetário equivalente à reprodução da força de trabalho - isto é, era o mínimo para garantir a subsistência do trabalhador. Fora fixado em uma média aferida por uma pesquisa no âmbito do setor urbano-industrial, e variava de acordo com a variação dos preços dos gêneros básicos em cada região. Porém, como não variava de acordo com a qualificação dos trabalhadores, ficando os qualificados em flagrante desvantagem, a acumulação tinha taxas muito satisfatórias para burguesia industrial. 0 salário mínimo igualava pela base.

Essa operação de igualar pela base reconvertia inclusive trabalhadores especializados à situação de não qualificados, e impedia - a formação precoce de um mercado dual de força de trabalho. Em outras palavras, se o salário fosse determinado por qualquer espécie de "mercado livre", na acepção da teoria da concorrência perfeita, é provável que ele subisse 
para algumas categorias operárias especializadas; a regulamentação das leis do trabalho operou a reconversão a um denominador comum de todas as categorias, com o que, antes de prejudicar a acumulação, beneficiou-a. (Oliveira, 2003, pp. 38-39).

O segundo ponto crucial é ação estratégica exercida pelo Estado. Este exerceu um controle administrativo efetivo sobre a crise do café preparando o caminho para o desenvolvimento da indústria. 0 Estado age para

\begin{abstract}
criar as bases para que a acumulação capitalista industrial, no nível das empresas, possa se reproduzir. [...] o Estado intervém para destruir o modo de acumulação para o qual a economia se inclinava naturalmente, criando e recriando as condições do novo modo de acumulação. [...] a imposição de uma distribuição de ganhos diferente entre grupos sociais, e a direção em que eles atuam é no sentido de fazer a empresa capitalista industrial a unidade mais rentável do conjunto da economia. (OLIVEIRA, 2003, p. 40)
\end{abstract}

Já a agricultura foi importante tanto como parte funcional das novas regras do jogo, porque lastreou financeiramente a transformação industrial ${ }^{10}$, quanto pelo fato de que fornecia produtos para o mercado interno contribuindo para não elevar os custos da reprodução do capital variável, o que interditaria altas taxas de acumulação de capital.

Revelador da particularidade do capitalismo periférico brasileiro é a integração harmônica entre industrialismo e agrarismo. Na periferia do capitalismo os modos de produção arcaicos e modernos não se repelem, mas se abraçam para formar uma totalidade coerente e muito particular de expansão capitalista. Exemplo disso é a função sui generis da acumulação primitiva entre nós.

No Brasil a acumulação primitiva não foi exclusivamente uma pré-condição para o desenvolvimento do capitalismo, como no caso Inglês, mas constituiu-se como um método permanente de expropriação de excedente que auxiliou tanto o arranque quanto o desenvolvimento contínuo do capitalismo industrial. Sob o agrarismo brasileiro, "o trabalhador rural [...] cultiva as lavouras temporárias chamadas de 'subsistência'; nesse processo, ele prepara a terra para as lavouras permanentes ou para a formação de pastagens, que não são deles, mas do proprietário." (OLIVEIRA, 2003, p. 43). Essa relação de trabalho ainda não teve fim; e por meio dela não se expropriou a propriedade de uma classe camponesa, mas seu excedente, que, transformado em capital, financia o capitalismo industrial. Assim em economias periféricas como a brasileira "a acumulação primitiva é estrutural e não apenas genética."

10 Em direção semelhante João Manuel Cardoso de Mello (1995) defende que foi a economia cafeeira responsável por gerar as condições básicas para o florescimento da indústria no Brasil. 0 "complexo exportador cafeeiro, ao acumular, gerou o capital-dinheiro que se transformou em capital industrial e criou as condições necessárias a essa transformação: uma oferta abundante no mercado de trabalho e uma capacidade para importar alimentos, meios de produção, bens de consumo e capitais, o que só foi possível porque estava atravessando um auge exportador." (MelLo, 1995, p. 101). 
A condição operária que advém no momento mesmo em que o capitalismo industrial está se colocando sobre seus próprios pés é que arcará com o ônus desta estrutura. Assim, a condição operária irá se configurar em meio aos constrangimentos de um tipo de capitalismo que se apoiou demasiadamente na exploração da força de trabalho concedendo-lhe muito pouco em troca.

\section{Condição operária “incompleta”}

Quando Castel elenca aquelas cinco condições que intervieram para que a condição operária se consolidasse, deixa fora de foco as condições políticas sob as quais uma condição operária se configura. Estas aparecem, em seu argumento, como algo excepcional. Nesse sentido, Castel retira a centralidade do movimento operário como alavanca que impulsionou o avanço representado pelas conquistas políticas que sedimentaram-se e configuraram a condição operária. ${ }^{11}$

Retomemos seu argumento. Sob a condição operária o mercado de trabalho encontra-se regulamentado. Isto quer dizer que a compra e a utilização da mercadoria força de trabalho dá-se em condições novas - isto é, não mais sob o reino absoluto da ortodoxia liberal - e que, particularmente, tais condições propiciam um novo lugar na sociedade para os trabalhadores. Na determinação desse novo lugar têm vez aquelas cinco condições destacadas, (não todas da mesma forma em todos os lugares, obviamente). Contudo, segundo entendemos, aquelas condições não independem do fator político, isto é, não independem do arranjo de poder entre as classes fundamentais - no caso do Brasil entre as classes fundamentais e o Estado, segundo Vianna (1999) e Santos (1987) a partir de 1919 e 1923, respectivamente. Assim, as condições destacadas por Castel antes são condições condicionadas pelo arranjo das relações de força entre as classes fundamentais e o Estado do que condicionantes destas relações.

O Estado sempre está presente interferindo na relação das classes fundamentais, seja pelo registro da ausência da regulação, quando sua presença se faz sentir pelo uso da força bruta para manter a ordem sempre que esta estiver ameaçada pelo movimento operário inquieto sob uma exploração desmedida; seja sob uma face reguladora, quando normatiza e faz cumprir algumas regulamentações necessárias à estabilidade política e social negando total autonomia de organização à classe operária.

A condição operária que foi se configurando no Brasil não foi acomodada no

11 Não estamos dizendo que Castel negue a política, mas tão somente que não lhe confere centralidade. Nos diz ele tão somente que: “[...] é realmente o Estado que parece ter tido um papel decisivo na constituição do direito do trabalho. Pelo menos até que uma parte da classe operária, que aderiu às reformas (como objetivo privilegiado ou como etapa de um processo revolucionário), entra em cena para por seu ponto de vista." (CASTEL, 1998, p. 436). 
vazio, mas em um lugar específico e sob determinadas condições. Dada a "impossibilidade" da universalização relativa da extensão dos direitos do trabalho para todos aqueles que eram a parte ocupada do mercado de trabalho - então nacionalizado, e sob determinado marco jurídico que expressava uma relação determinada entre trabalho-capital-Estado - a condição operária configurou-se restrita à área urbano-industrial, pois seu fundamento era político-econômico. Expressão disso, o corporativismo foi no Brasil um tipo de arranjo institucional que regulou o conflito capital-trabalho desfavoravelmente à classe trabalhadora industrial, na medida em que dissimulou a dominação burguesa sob signos de universalidade. Um dos graves efeitos do corporativismo para a configuração da condição operária no Brasil foi a negação de um "estatuto coletivo do trabalho", que aparece como uma das condições fundamentais destacadas por Castel para a superação da condição proletária.

Do ponto de vista das relações de produção presentes no Brasil, a relação capital, stricto senso, estava circunscrita ao setor urbano-industrial da economia. Nesse lugar emergiram "naturalmente" as condições para a auto-organização da classe operária para a luta, quer seja, radicalmente contra o capitalismo, caso dos anarquistas, quer seja, pela a regulamentação das relações de trabalho, caso dos socialistas (SILVIA, 1977). ${ }^{12}$

No que diz respeito ao setor agroexportador podemos deduzir que o assalariamento era a relação predominante, todavia segundo Santos (1987) a regulação do trabalho não chegou lá tão cedo.

Já no que diz respeito ao setor agrário de produção de bens de subsistência para o mercado interno, podemos afirmar que as relações de produção eram galgadas por laços pessoais de dependência. A estrutura social confrontava uma minoria de latifundiários a uma ingente massa de caboclos com suas proles que eram impelidos a buscarem o favor de um latifundiário que concedesse um pedaço de terra para trabalharem em troca de meios de subsistência (OLIVEIRA, 2003). 0 excedente da produção, descontada uma ínfima parcela para o produtor, era apropriado pelo dono da terra. Como essa relação não originava uma renda consideravelmente significativa a ponto de fazer circular localmente um fluxo de renda - provocando o surgimen-

12 Sobre as condições sociais de produção das possibilidades de luta organizada da classe trabalhadora urbano-industrial Cardoso (1962) defende que e o movimento operário não obteve conquistas significativas, na I República, porque a classe era heterogênea (porque composta por um desenvolvimento industrial descontínuo) e não tinha tradição de luta operária (fator acentuado pelo fato de que grande parcela do proletariado era de origem rural). Sob tais condições objetivas o proletariado reagia violentamente porque eram incapazes de compreender a própria situação. Tal diagnóstico pressupõe, equivocadamente, uma consciência de classe ideal; como o proletariado não perfazia essa consciência atribuída, era visto como incapaz. Nesse sentido, o autor enfatiza que a atitude do proletariado era marcada pela "incapacidade de compreensão dos mecanismos de manutenção da ordem capitalista industrial, e consequentemente, pela impossibilidade de reação organizada a ela [...]. No conjunto, a ação operária estava condenada a ser, ao mesmo tempo e ambiguamente, violenta e impotente." (CARDoso 1962, pp. 111-112). 
to de uma oferta galgada em uma relação de assalariamento capaz de impactar na composição e funcionamento da estrutura social - entendesse o que condicionava a imobilidade da estrutura social de uma economia pré-capitalista. Bem como, a quase que impossível organização política dos subalternos em tais condições, objetivamente fragmentados.

A possibilidade, ou não, de generalização dos direitos do trabalho para toda classe trabalhadora diz respeito, portanto, a uma equação política. Pois depende da força relativa das classes fundamentais nas diferentes relações de produção. Aqui se impõem o problema do capitalismo dependente e subdesenvolvido, ou o problema do desequilíbrio do desenvolvimento econômico regional brasileiro. Que fez pesar ainda mais o "tacão de ferro" do capitalismo periférico sobre a condição operária em formação.

Por outro lado, a "impossibilidade" da generalização concreta dos direitos do trabalho, que equivaliam de fato à cidadania regulada ${ }^{13}$, atrelada à solução brasileira dada à questão agrária, fazia afluir para os centros industriais hordas errantes de trabalhadores que ao aumentarem as fileiras do exército industrial de reserva, comprimiam a remuneração daqueles que conseguiam se vender para o capital industrial ${ }^{14}$. Aqui evidencia-se outra implicação que fez da condição salarial no Brasil "incompleta": os baixos salários não propiciaram aos trabalhadores um consumo diferencial de bens duráveis, e o padrão de vida só foi alterado, minimamente, por que a desigualdade social de nossa sociedade era, sem exagero, desde sempre, imensa - suas raízes podem ser localizadas na sociedade escravista (FERNANDES, 2005), onde a classe latifundiária se apropriou da riqueza produzida aqui quase que absolutamente por séculos. 0 desenvolvimento do capitalismo industrial aprofundou do seu modo esse abismo social.

Colocados os termos da equação política, já podemos aferir um resultado. Em geral, podemos afirmar que as relações de produção avançaram favoravelmente aos trabalhadores onde a organização política permitiu. A relação de mútua determinação (MARX, 2008) entre a estrutura social - que é o suporte social para a rela-

13 Noção de cidadania regulada acentua o caráter incompleto da condição operária brasileira. Segundo Santos (1987) cidadania regulada é um tipo de "cidadania cujas raízes encontram-se não em um código de valores políticos, mas em um sistema de estratificação ocupacional, e que, ademais, tal sistema de estratificação ocupacional é definido por norma legal. [...] A cidadania está embutida na profissão e os direitos do cidadão restringem- se aos direitos do lugar que ocupa no processo produtivo, tal como reconhecido por lei. Tornam-se pré-cidadãos, assim, todos aqueles cuja ocupação a lei desconhece". (SANTos, 1987, p. 68 grifo nosso).

14 Nesse sentido Cardoso (2010) afirma que "a partir de determinado momento no quinto século brasileiro, o mundo urbano passou a exercer irresistível força gravitacional sobre essa população [camponesa], gerando um movimento avassalador de pessoas e famílias na direção das cidades em um espaço muito curto de tempo. [...] As promessas de direitos sociais (muito especialmente o salário mínimo), além, é claro, de acesso a serviços públicos de educação e saúde, sempre valorizados pela população pobre, parecem ter atraído, além das populações desgarradas do campo, muitos daqueles antes submetidos aos padrões tradicionais de dominação [...] que, de outra maneira, talvez tivessem permanecido ali." (CARDoso, 2010, p. 225) 
ção entre os demais fatores, ao mesmo tempo em que muda também de acordo com as transformações daqueles - as relações de produção - relação capitalista (de exploração velada e dominação impessoal) e relação tradicional ou pré-capitalista (de exploração "explícita" e dominação pessoal) - e as forças produtivas - agricultura para subsistência; agricultura para exportação; indústria para o mercado interno e/ ou externo, as suas correspondentes técnicas empregadas - conformam os poderes diferenciais dos grupos envolvidos. Não é de se estranhar que aqueles trabalhadores alocados nas condições das relações de produção pré-capitalistas, sem condições políticas para alterarem diretamente sua condição, sejam atraídos para o centro industrial com suas promessas de integração social e acesso a direitos. Apesar de sua configuração incompleta a condição operária era um belo horizonte para esses trabalhadores que buscavam na sociedade industrial uma vida melhor .

Em consequência, forma-se um enorme exército industrial de reserva pressionando o mercado de trabalho do setor urbano-industrial e, assim, tem-se mais uma implicação para a formação da condição operária no Brasil: com uma alta taxa de rotatividade dos postos de trabalhos, dada a dimensão do exército industrial de reserva, não houve por aqui, a não ser para a condição de operário qualificado, como observou Castel para a França, uma fixação do trabalhador ao posto de trabalho. Pelo contrário, os postos é que eram fixos e o trabalhador rotativo.

\section{Considerações finais}

Vimos, então, acompanhando Castel, que um tipo de relação salarial que é correlata à condição proletária já trazia os elementos básicos de uma relação salarial moderna e, portanto, os elementos a serem superados para o estabelecimento de uma nova relação salarial. Uma relação salarial que assumirá determinada configuração, tal como a anterior, segundo o arranjo de fatores técnicos (determinantes da organização da produção), econômicos (ligados à esfera do consumo, intrinsecamente atrelada à produção) e políticos (que remetem à esfera jurídica do Estado e, portanto, das leis, e ao plano da sociedade civil, onde as classes se organizam) que, finalmente, conformarão um arranjo social particularmente "novo".

Nesse sentido nossa investigação inclinou-se sobre o processo de transformação da relação salarial que no Brasil esteve circunscrita ao setor urbano-industrial da economia capitalista a partir do século XX. Entendemos, assim, que o surgimento de uma nova relação salarial pressupõe a transformação de uma relação salarial que já existia antes, com outro conteúdo. Pressupõe, portanto, que com o desenvolvimento industrial desenvolve-se também um proletariado que trabalha, é remunerado, consome, perfaz um certo padrão de vida e organiza-se politicamente sob 
determinadas condições. Tudo isso "antecipa a relação salarial moderna sem ainda manifestá-la em sua coerência." (CASTEL, 1998, p. 418).

Por sua vez, a relação salarial que se configura no interior do mercado de trabalho urbano-industrial brasileiro é bem particular. Assim pudemos afirmar que a relação salarial assume um caráter nacional. Nesse sentido é que propusemos pensar a transição da relação salarial no Brasil. Diferentemente dos países do centro do capitalismo, no Brasil, tal transição aconteceu no momento mesmo em que o capitalismo industrial estava erguendo-se para caminhar sobre seus próprios pés. Falamos, pois, de uma situação única, e, que imprimiu algumas particularidades à transformação da relação salarial e configuração da condição operária no contexto brasileiro.

A despeito dos limites que o capitalismo dependente impôs às alternativas da burguesia nacional, esta conduziu sua dominação de tal modo que é ela a que se deve, também (e não só ao capitalismo "difícil") uma configuração incompleta da condição operária no Brasil. Foi ela que dominou tornando

\begin{abstract}
permanente a exclusão (total ou parcial) do grosso da populção não possuidora do mercado e do sistema de produção especificamente capitalistas; e dinamismos socioeconômicos débeis e oscilantes, aparentemente insuficientes para alimentar a universalização efetiva (e não apenas legal) do trabalho livre, a integração nacional do mercado interno e do sistema de produção em bases genuinamente capitalistas, e a industrialização autônoma. Desse ângulo, dependência e subdesenvolvimento não foram somente "impostos de fora para dentro". (FERNANDEs 2005, p. 262 - grifo nosso)
\end{abstract}

Vale dizer, uma condição operária incompleta, também não.

\title{
Referências bibliográficas
}

BARbosA, Alexandre de Freita. O mercado de trabalho antes de 1930. Novos Estudos Cebrap, São Paulo, mar. 2008, pp. 91-106, 2008.

BocchI, João idelbrando. Crises capitalistas e a escola francesa da regulação. Pesquisa e Debate, São Paulo, volume 11, número 1 (17) pp. 26-48, 2000.

BRAGA, Ruy. A nostalgia do fordismo, elementos para uma crítica da Teoria Francesa da Regulação. Tese (Doutorado em Ciências Sociais), Universidade Estadual de Campinas, 2002.

Braudel, Fernand. Civilização Material, Economial e Capitalismo, Séculos XV-XVIII. São Paulo, Martins Fontes, 1996.

Cardoso, Adalberto. (2010). A Construção da Sociedade do Trabalho no Brasil: uma investigação da persistência secular das desigualdades. Rio de Janeiro, Editora FGV.

Cardoso, Fernando Henrique. Proletariado no Brasil: situação e comportamento social. Revista Brasiliense, São Paulo, n. 41, maio/jun. de 1962. 
CASTEL, Robert. As metamorfoses da questão social: uma crônica do salário. Petrópolis, RJ: Vozes, 1998.

FERnAndes, Florestan. A Revolução Burguesa no Brasil: ensaio de interpretação sociológica. 5a ed., São Paulo, Globo, 2005.

Furtado, Celso. Formação Econômica do Brasil. 23ạ ed. São Paulo, Editora Nacional., 1989.

Gomes, Ângela Maria de Castro. A Invenção do Trabalhismo. São Paulo: Vértice, Editora Revista dos Tribunais; Rio de Janeiro: Instituto Universitário de Pesquisas do Rio de Janeiro, 1998.

Hobsbawm, Eric. A era das revoluções (1789-1848). Rio de Janeiro: Paz e Terra, [orig. ingl. 1962] 1996.

MARX, Karl. O Capital, Crítica da Economia Política. São Paulo, Ed. Nova Cultural, 1996.

2008. Contribuição à crítica da economia política. São Paulo, Expressão Popular,

Mello, João Manuel Cardoso de. O capitalismo tardio: contribuição à revisão critica da formação e do desenvolvimento da economia brasileira. Campinas, Editora da UNICAMP, IE, 1995.

Nascimento, Elimar Pinheiro do (1993). Notas a respeito da Escola Francesa da Regulação. Revista de Economia Política, vol. 13, no 2 (50), abril-junho de 1993.

Oliveira, Francisco. . Crítica à Razão Dualista - O ornitorrinco. São Paulo, Boitempo, 2003.

PolanYI, Karl. A Grande Transformação: As Origens de Nossa Época. 2ª ed., São Paulo, Campus, 2000.

Santos, Wanderley Guilherme dos. Cidadania e Justiça. Rio de Janeiro: Ed. Campus, 2 ${ }^{\mathrm{a}}$ edição, 1987.

Silva, Ligia Maria Osorio. Movimento sindical operário na Primeira República. Dissertação de Mestrado (Ciência Política), UNICAMP, 1977.

Vianna, Luiz Werneck. Liberalismo e Sindicato no Brasil. 4⿳亠丷a ed. (revisada), Belo Horizonte, UFMG, 1999.

Recebido em abril/2015.

Aprovado em outubro/2015. 